\title{
The Anomie and Norm of Network Language Communication
}

\author{
Xin Zheng \\ School of Foreign Languages, Shanxi Normal University, Linfen 041000, China
}

\begin{abstract}
Network language has enriched and promoted language development on the one hand. On the other hand, the randomness of network language has made itself have a lot of irregularities and imperfections. Due to the context of network communication and the characteristics of main users, there exists the anomie from the aspects of language rules and content in network language, such as grammar, vocabulary and pragmatics, which causes the communication barriers in different communicative communities and the negative impact on the young Internet users and the development of modern Chinese. Therefore, it is an urgent problem to strengthen the research on the anomie of the network language and put forward the countermeasures to normalize the network language.
\end{abstract}

Index Terms-network language, communication, anomie, norm

The network language is a kind of language phenomenon, which is widely used with the development of network and high technology and refers to the language relating to the network and on-line communication, including network terminology, chat language and words relating to network etc. The concept of "anomie" is first proposed by Durkheim, a French sociologist, and it literally means "the lack of norm", mainly referring to a disordered social condition that lacks regulation and institutionalization to personal desires and behaviors. Merton, a sociologist in the US, regards "anomie" as a "the absence of norm", that is, people do not have extensive recognition of the existing social norms, so that social norms lose the authority and effectiveness of controlling people's actions (Xiong, 2008). This paper holds that "anomie" refers to the psychological disorder of social members caused by the weakening and destruction of traditional values and social norms in the process of modernization. Anomie not only refers to individual behavior, it also involves group behavior. As a special kind of social dialects, network language appears to meet the needs of network communication, which has brought great impact on the traditional language. The positive internet language will be retained and enrich the modern Chinese, while it is an intellectually worthwhile goal for us to alert and reflect the undesirable network language.

\section{The ORIGIN OF NeTWORK LANGUAGE ANOMIE}

The language modal is the product of the environment, so the network environment determines what the network language is. The characteristics of network are dummy, timely and so on, which are different from the traditional media'. Due to the various functions the network language used to perform and conditions when it generated, the expression and effect of network language are also diverse, just like the difference between written language and oral language in real life. As a social dialect, network language is not isolated and has an interactive relationship with society, whose emergence has a profound social foundation (An, 2010). On the one hand, the generation of network technology and the widespread use of Internet provide the material space for generating network language. On the other hand, the sharp increase of netizen constitutes the basis of population who use network language. Under the news censorship system of traditional media, it is difficult for public to obtain space to express freely, while on the Internet where regulation is not easy to execute, netizens have gained unprecedented freedom of expression. In the network world, the lack of language regulation and fuzzy right-wrong standard break linguistic rules, and some users even ignore the tradition of language specification, therefore, the soil of the network language anomie is formed (Huang, 2008).

\section{The REPRESENTATION OF Network LANGUAGE ANOMIE}

Although the network language is not dissociated from the Chinese language system, it can't fundamentally violate the basic rules and principles of voice, vocabulary and grammar, and it is quite different from the general language. The network language is vivid, free, kind and humorous, especially close to life, at the same time, is of varying quality. The network language is to the public from small. Internet users transform some Chinese and English vocabularies and link and inlay words, images, symbols freely, creating new words mixed with numbers, English and Chinese letters, which are totally inconsistent with the Chinese standard expression of the network language. Even some netizens spread vulgar, dirty and violent language on the Internet so that the problem of anomie can't ignore any more. On the one hand, the network language has enriched the national language. On the other hand, the network language anomie has brought certain impact on national language and modern Chinese 
standardization which not only destroys the purity and health of Chinese, but also has a negative impact on the development of young people (Wang \& Zhang, 2009).

\section{A. The Anomie of Phonetic Application}

New and original phonetic pattern of manifestation is a common network communicative method to attract the attention of the netizens to express certain special wishes and emotions. One is the abuse of the homonym, for example, “886” refers to “拜拜了”; “3344” refers to “生生世世”. The two is the abbreviation, such as “GG” represents “哥哥”; “FB” means “腐败”; “BB (Bye Bye)” represents “再见”; “FT (Faint)” means “晕倒”. The three is the monosyllable instead of disyllable. Generally speaking, the one Chinese character has one syllable. There are some phenomena of replacing two syllables with one syllable for the convenience of typing, for example, “表” represents “不要”, “酱” represents “这样” and so on. The reconstruction of the strange vocabularies increases the misunderstanding of network information so that the ordinary people don't know what is said. If not regulated and guided effectively, it's easy to do harm to Chinese and cause some reading difficulties.

\section{B. The Anomie of Lexical Application}

The first one is the bilingual overlap, such as “漂漂” means “漂亮” and “东东” refers to the “东西”. Obviously, these examples are beyond the modern Chinese. The second is the combination of Chinese and English, such as “等 待 ing” represents “在等待之中”, “有事 call 我” means “有事找我” and so on. The next is the distortion of the vocabulary, for example “偶”instead of “我”, “灌水” instead of “随意写”. Four is the use of misspellings, such as “师付(傅)”，“风度扁扁(翩翩)”, 网巴(吧) etc.. The misuse of words not only directly leads to people’s misunderstanding who are not familiar with the network language, but also increases the difficulties of communication on the Internet.

\section{The Anomie of Grammatical Rules}

The anomie of grammatical rules is an important representation of the anomie of network language. Netizens have greater randomness in using network language, and grammatical rules are often not followed. Grammatical deviation is prominent, such as “我百度一下”; “别忘了伊妹儿我”; “他很阳光”; “有急事, 走先” etc. These strange statements go everywhere in the network language, which violates the normal Chinese word formation and grammatical rules and undermines the integrity and purity of the Chinese.

\section{The Anomie of Language Content}

The use of language embodies the moral consciousness, moral standards and moral values of the individual or society. The secrecy of netizens in the virtual world leads to the improper language in some official occasions, so that we can get the catharsis of personality. In the absence of supervision and unified standard, users are free to create network language according to their preferences. Therefore, some poor taste, moral decay, vulgar expressions diffuse in the network world, resulting in the anomie of network language and the strong shock towards linguistic norms in society. Some expressions and implied content on the Internet even contain the anti-marxism doctrine which brings great negative influence on socialist morality and the network language environment, affects the healthy development of network culture, and ultimately hurts the interests of the majority of netizens.

\section{E. Language Teaching Is Impacted}

Language is associated with a nation's way of thinking, emotion, and sub-consciousness. The network language anomie has quietly influenced and even permeated into teenagers' thinking that pursue something new and original, so that cyber language has become a kind of word game to show off their "literary grace" and "personality". The language anomie phenomena such as intentional typos and perverted meanings have negative affect not only on the use of Chinese for students, but also on language teaching. A large number of network languages are integrated into students' diary, composition and even daily communication and become a new fashion that we all strive for.

\section{The Cause of Network Language AnOmie}

\section{A. The Contextual Characteristics of Network Communication Are the Objective Conditions of the Network Language Anomie}

The Internet and its derived communicative approach are changing the modern life and culture. Differing from the face to face chat in reality and written communicative context, the contextual characteristics of network communication provide the soil and new materials for network language, and also are the objective conditions to language variation.

First, the convenience of the network communication is the catalyst for the anomie of network language. In the information age, in order to express ideas quickly, Internet users choose words as the first choice which can be knocked out in the fast and easy way, at the same time, the meanings of these wrong words can be understood. Therefore, this kind of word soon is recognized by Internet users. 
Second, the virtuality of the network provides a fertile ground for the network language anomie. The biggest difference between virtual communication on the Internet and reality communication lies in anonymity that communicative subjects' relationship shows. Network hides people's real identity, so they become "no mark" subjects of network and aren't controlled by the social role and responsibility. To a large extent, Internet has become a place where people can advocate self and create something new and original without traditional barriers. It is easy to induce and expose all kinds of ugly and evil factors in the depths of human nature. This kind of context with great free and low constraint provides a carrier for the free play of the network language (David, 1999). Internet users have been feeling of liberation and impulsion, and language norms of real communications are broken from time to time so that a variety of unconventional or unorthodox languages become the normality on the Internet (Chang, 2000).

Third, the openness of network communication provides a propagation platform for network language anomie. The Internet is an open electronic space, which realizes the information communication without considering time and space, and users can freely gallop and interact with anyone in the network. Everyone can use the Internet at anytime and anywhere to communicate freely and obtain information and transmit it on an equal basis. The wide use of network language, as a communication tool on the Internet, provides a communication platform for the phenomenon of its anomie.

\section{B. The Main Source of Network Language Anomie Is the Characteristic of the Main Body of Net Users}

In the context of information society, people have some alienation representations. "The material level is represented by technology alienation and symbol alienation; the mental level is manifested as rational alienation and spiritual alienation; the institutional level includes communicative alienation and normative alienation" (Peng \& Li, 2011, p.25). [7] According to the thirtieth Internet Statistics report released by China Internet Information Center in July 2012, the $56.8 \%$ of Internet users in China are beyond 29 and youngster is the mainstream group of netizens. The psychological characteristic and emotional state of young netizens are consistent in a certain degree, and the use of Internet language is full of vigour and rebellious consciousness. The Internet users choose the network as the place to exchange and express emotion and to enjoy the "ideological emancipation" and the freedom of speech brought by the network. At the same time they are vulnerable to the curiosity and sense of achievement owing to destruction, deliberately alienating from the connotation and preciseness of traditional culture, and love to create the so-called fresh words and spread each other in the network communication, otherwise they will be regarded as obsolete and outdated people. The phenomenon of network language anomie is a kind of expression and refraction of young netizens' outlook on life and rebellion ( $\mathrm{Li}, 2007)$. "Self-consciousness" promotes young netizens to create, promote and use non-standard language, which is the main cause of network language anomie.

\section{The Misunderstanding of the Language Communication Responsibility Is the Propellant of the Network Language Anomie}

"Language is the most important communication tool for human beings", this is the consensus of all sociologists and linguists. If the language can't be used accurately, the information can't be transferred correctly among people, and the normal communication will be affected. The state has formulated a series of laws and regulations, such as the Constitution of the People's Republic of China and the National Language and Character Law of the People's Republic of China, to standardize the Chinese characters and language transmission. However, most teenager netizens only recognize the value of language from the "communication tool", and think that the standardization of language is a matter of language experts. They use our native language casually in online communication activities. All kinds of non-standard network languages have a negative impact on the knowledge storage and the correct use of language for the Internet users, especially teenagers. Therefore, regulating language communication is the common responsibility of the whole society (Guo \& Hao, 2006).

\section{The Significance of The Network Language Specification}

\section{A. The Nature and Location of the Network Language}

The nature and location problem of the network language cause great controversy in the society and academic circles. There are many people who hold positive attitudes, while criticism and skeptics also have, even some announce that the network language destroys the traditional Chinese that with the history of thousands years, and it is the cultural garbage and spiritual pollution which must be resolutely banned. Since the social and academic circles have so different opinions about this phenomenon, what kind of scientific attitude should we hold to treat cyber language?

We think that the network language is a language variant of the general language or the universal language in the network environment, which belongs to the social dialects. Network language does not have its own independent phonetic system, grammar system and basic vocabulary, and it uses all of them in general language or national language and some special words which belong to the category of the general vocabulary. Since the essence of network language is a social dialect, it only has its own distinctive personality and characteristics in vocabulary, and it is just a kind of general vocabulary in the universal language vocabulary system and does not belong to the basic 
vocabulary, therefore, we should maintain a natural attitude towards the development of the network language rather than blaming or even killing, because it is conducive not only to develop the Internet communication, but also to enrich national language vocabulary and promote the development of the national language. However, due to the rapid development of Internet, the number of netizen and the influence of network language are increasing. We must pay attention to the standardization of network language and make it develop in a right, healthy and standardized way.

In a word, our scientific attitude to the network language is to notice the guidance and strengthen the norms. Although the network language has been greatly developed, the standard work has not been done enough today, so the priority is to strengthen the specification of the network language.

\section{B. The Significance of the Network Language Specification}

The network language is also a part of the Chinese language, and it is also obliged to follow the development of Chinese traditional language. Kant thinks that [10] all languages are the marks of thought, on the contrary, the most effective way of ideological marking is to use the extensive tool-language to understand ourselves and others. Chinese language and character are the carrier and symbol of Chinese culture. It is the obligation for every Chinese citizen to inherit and carry forward the Chinese traditional culture, and to strive to maintain the uniqueness of Chinese traditional characters, making the Chinese is always the unique culture of our nation rather than a combination of countless civilization. To maintain the standardization of Chinese characters is also to maintain the dignity of China. Now, the international status of Chinese characters has been rising, and the Confucius colleges are established to adapt the international trend of learning Chinese. Foreigners begin to learn Chinese in warm today, and we, as the member of the Yellow Emperor, should set an example and use the language normatively, so that foreign netizens who surf the Chinese website can see the healthy, positive, civilized and upward content. The standardized use of Chinese language can reflect the dignity of the country and the confidence of the nation. The generalization of network language impacts the development and progress of the Chinese language, and it is also invading the campus, especially the primary and middle school students whose outlook of the world, the life and the values are forming. They do not yet grasp the language ability perfectly, and are in a critical period of language acquisition. Therefore, if they can't often come into contact with the standard language even the uncivilized language input, which will affect their language output in the future.

\section{Measures For the Network Language SpecificAtion}

The specification of network language is to standardize the Internet terms that are illegal, unethical, and strange. Chen Yuan mentions in his sociolinguistics methodology: "variation and norm are the unity of contradiction. There is no norm without variation, and no variation can be seen without norms. Changes and norms are dialectically unified" (Kant, 2005). The writer agrees with the view that language variation can promote the development of language. In the process of language development, we cannot change without restriction. We need to guide correctly. The norm mentioned in the article is not a kind of negative change, but a specification to unreasonable part of variation in order to minimize the negative influence of network language. Therefore, norms are not mandatory, but more focus on guidance. Network language has surpassed the original use scope, which spreads from the network to our daily life, study, and work. The specification of network language can't be limited to the Internet, and it should be the common responsibility of every person who uses the network and cares about the development of the network. The author puts forward the following suggestions, and hopes to provide some valuable references for the usage and scientific research of the network language.

\section{A. Dialectical Treatment Is an Effective Prerequisite for the Standardization of the Network Language}

On the one hand, the network language is vivid and lively, and it is the important motive force or way to enrich and develop the language. On the other hand, network language is a new thing, and has many irregularities and imperfections, some of which have affected the standardization and purity of modern Chinese and are not conducive to the construction of network civilization. Therefore, the network language must be treated dialectically and be guided in the right way, so that it can play its strengths in a specific range for the development of network communication.

First, we should guide the standardization of the network language with a tolerant attitude. Marxism believes that the language system is open and not static. It is always on the process of constant renewal and development and constantly enriches with the development of economy and society. Therefore, we should strengthen the standard guidance of network language, stop uncivilized language, actively advocate the use of network language in line with Chinese word-formation and grammatical norms, and develop the correct habit of language using.

Second, we should set up a correct concept of network language standard. "The norm is to promote development, and limiting the development is not a real norm." (Yu, 2001, p.27) The human language has always been in the unity of opposites between norms and anomie. Chen Yuan, a linguist, said: "it is not appropriate to absorb or reject all variations of the language. The correct way is to distinguish: positive changes that are conducive to language development should be absorbed, and negative changes that are not favorable should be abandoned. Only in this 
way can the language develop along a healthy road" (1994, p.115). Although we can't stop the development of network language, the phenomenon of anomie shouldn't be let slide.

\section{B. Marxism's View of Language Is the Effective Principle of the Standardization of the Network Language}

Marxism's view of language is an organic part and one of the most important contents of Marxism's philosophy. Marxism thinks that language is the carrier of thought and a reflection tool for objective reality. In Marx's view: language is only the expression of real life; real life is the foundation and boundary of language; the language is interpreted by life.

The standardization of the network language must adhere to the principle of Marxism's view of language. Marx thinks: "language is the direct reality of thought, and society is dependent on language. Social production and public life without language participation are unthinkable". Lenin points out that "language is the most important human communication tool". Language comes into being, developing and dying along with the needs, development and extinction of social communication. The language can embody the user's ideological quality and moral sentiment. Network language is a relatively stable social and cultural group and its essence is a social variation in modern Chinese and the result of language change caused by social and cultural changes. The current network language anomie must be guided and standardized by Marxism's view of language.

\section{Concise Expression and Healthy Content Are the Effective Requirements for the Standardization of the Network Language}

Language is a communication tool, and the concise expression and healthy content are the basic requirements for the effective communication between the two parties. Network language is also a kind of language activity, and it can be widely spread on the Internet and real life, which shows that it has strong vitality. If the content of the network language can't be understood, it will greatly affect the communication and lose the original meaning of the language. Therefore, the network language must be able to clearly reflect the ideological content and express the true feelings of the communicators. Healthy content is an important part of the network language specification. When using network language, its content should be positive and consistent with the socialist core value system and social mainstream values, helping to improve the overall moral level of the society. Some unhealthy, low and coarse network languages will bring great negative impact on the network language environment. Hence, standardizing network language should advocate language civilization, purify the network language environment, improve the quality and appreciation ability of network language, and form the correct value orientation.

\section{The Promotion of Media Literacy Is an Effective Means for the Standardization of the Network Language}

Media literacy refers to people's understanding, utilization and participation in the mass media. It includes the ability to acquire, discriminate, select, use and distribute media information, the familiarity of media, the cognitive level of information dissemination characteristics, and the ability to evaluate the media environment. In the information society, the audience's ability to deal with information has become one of the most basic abilities of people in the modern society. Network is a new medium. It is the effective means to clean up the network environment and standardize the network language by strengthening media literacy education and improving the media literacy of all Internet users.

First, we should strengthen the moral education of the network language. Network language specification is not only a problem of language use, but also depends on the improvement of netizens' media literacy and the enhancement of the whole society's spiritual civilization and moral level. We should strengthen the education of the national language and moral accomplishment and make it play a role in the network society in order to build a network language and moral education system based on the excellent language culture and guide users to consciously practice moral behavior on the Internet.

Second, we should strengthen the publicity of the standard network language. In order to mobilize the enthusiasm of many parties and strengthen the propaganda of the construction of the network language civilization, this concept will be deeply rooted in the hearts of the people. We should propagate the network etiquette, advocate the language civilization, form the public opinion environment that resists the vulgar style of the Internet fundamentally, and purify the network language.

Third, we should create a civilized network language environment. Society is the external soil of the network language, and a positive network environment needs a healthy and harmonious society as the support. Therefore, actively creating a good social atmosphere and enhancing the Internet users' awareness of Internet morality are beneficial to build Internet civilization and form a civilized network language environment.

\section{E. The Formulation of Policies and Regulations Is an Effective Guarantee for the Standardization of the Network Language}

First, we should strengthen the specification awareness of network language. Network language anomie is not only a problem of language, but also reflects a kind of cynical way of life that has a negative impact on people's mood, thinking and habits. Therefore, Internet users' specification awareness of network language must be 
strengthened and the legal concept should be set up to standardize, manage, flourish and develop the network language.

Second, the rules and regulations of the network language should be formulated. It is high time to formulate relevant laws and regulations and limit network language anomie. It is also necessary to limit the network language use, and network vocabulary must meet the modern Chinese vocabulary and grammar regulations, especially in official documents, textbooks and news reports. The unauthorized development of network language will have a negative impact on Chinese, and it will hinder the promotion of Chinese in the world. Formulating Internet language can maintain the health and purity of Chinese.

Third, we should strengthen the information management on the Internet. Network media should take the lead in the use of standard modern Chinese, actively disseminate the concept of using correct network language, and provide a medium platform for improving the network language literacy of the whole nation. The regulatory authorities should control all kinds of bad language online from the source, eradicate their survival soil, and create a good cyberspace and clean communicative platform for netizens.

\section{CONCLUSION}

Network language has sprawled and spread rapidly to all places outside the network, which is the trend of language development. In the face of this trend, what we need to do isn't force to stop, but to reasonably regulate and guide. It is not easy to standardize the network language, so it needs the common efforts of the Chinese people who are concerned about the development of the network and language.

\section{REFERENCES}

[1] An Zhiwei. (2010). The social influence of contemporary network language. Theory Journal, 4, 114-116.

[2] Ao Yongchun \& Chen Chunzhu. (2013). The anomie and norm of network language communication. Ideological and Political Education Research, 1, 125-128.

[3] Chang Changfu. (2000). Mass-communication: influence research paradigm. Beijing: China Social Sciences Publishing House.

[4] Chen Yuan. (1994). Language and human. Shanghai: Shanghai Educational Publishing House.

[5] David·Bovano. (1999). Sociolinguistics. Beijing: China Renmin University Press.

[6] Guo Duling \& Hao Huaijie. (2006). The anomie and norm of network language. Modern Chinese, 6, 74-75.

[7] Huang Jianbo. (2008). The social generative space of network language and its grammatical rules. Youth Studies, 4, 14-19.

[8] Kant. (2005). Practical anthropology. Shanghai: Shanghai People's Publishing House.

[9] Li Rui. (2007). The anomie and consideration of network communication. Journal of Hubei University of Police, 4, 91-94.

[10] Peng Xiaolan \& Li Ping. (2011). A new representation of alienation in the information society. Ideological and Political Education Research, 1, 25-28.

[11] Wang Jian \& Zhang Cong. (2009). Analysis and countermeasures of network language anomie. Journal of Jilin Normal University (Humanities \& Social Science Edition), 4, 71-73.

[12] Xiong Xiaoping. (2008). Analysis of anomie in network propagation. Jiangxi Social Sciences, 7, 221-225.

[13] Yu Genyuan. (2001). Chinese online language dictionary. Beijing: China Economic Publishing House.

Xin Zheng was born in Taiyuan, Shanxi in 1993. She received her bachelor's degree in English from LvLiang University, Shanxi in 2016.

She is currently a postgraduate studying for her master's degree and majoring in Foreign Linguistics and Applied Linguistics in Shanxi Normal University. Her research interests included sociolinguistics, second language acquisition and cognitive linguistics. 